\title{
Asymmetric Coupling of GDP and Emissions in the Coronavirus Pandemic-The Case of Taiwan
}

\author{
Yu-Chieh Chang1, Sheng-Ming Hsu' ${ }^{2}$, Ching-Cheng Chang ${ }^{3}$, Shih-Hsun Hsu ${ }^{1 *}$ \\ ${ }^{1}$ Department of Agricultural Economics, National Taiwan University, Taiwan \\ ${ }^{2}$ Department of Applied Economics, National Chung Hsing University, Taiwan \\ ${ }^{3}$ Institute of Economics, Academia Sinica, Taiwan \\ Email: ^m577@ntu.edu.tw
}

How to cite this paper: Chang, Y.-C., Hsu, S.-M., Chang, C.-C., \& Hsu, S.-H. (2020). Asymmetric Coupling of GDP and Emissions in the Coronavirus Pandemic-The Case of Taiwan. Modern Economy, 11, 1441-1450.

https://doi.org/10.4236/me.2020.118102

Received: July 2, 2020

Accepted: August 7, 2020

Published: August 10, 2020

Copyright $\odot 2020$ by author(s) and Scientific Research Publishing Inc. This work is licensed under the Creative Commons Attribution International License (CC BY 4.0).

http://creativecommons.org/licenses/by/4.0/

\begin{abstract}
Recently Helm (2020) provides an excellent review and preliminary assessment of the environmental impacts of the Coronavirus. He concludes that "The evidence from the pandemic is that it is not the case that decoupling has occurred at the global level, or even at the European level. Emissions and GDP have both fallen sharply" (p. 3). Using the case of Taiwan, this study provides a local evidence to support Helm (2020)'s proposition. GDP and emissions in Taiwan have been highly correlated in the coronavirus pandemic. However, we found that there exists a significant asymmetry of the correlation (or coupling) between GDP and $\mathrm{CO}_{2}$ emission under each period of prosperity and depression from 2005 to 2020. In this respect, the analysis of the causal link between $\mathrm{CO}_{2}$ emission and GDP under the depression period like that in the coronavirus pandemic cannot be considered as a trivial duplicate of the analysis under the prosperous period.
\end{abstract}

\section{Keywords}

Coronavirus, Climate Change, Greenhouse Gas Emissions, Asymmetric Adjustment, Decoupling

\section{Introduction}

Coronavirus disease 2019 (COVID-19) cases spread rapidly and expand early in 2020 in China, Republic of Korea, Japan, Europe (mainly Italy, France and Spain) and the United States. Increasing stringent measures were put in place by their governments in an effort to isolate cases and stop the transmission of the virus. However, these stringent measures have led to a total economic shutdown 
and the rising unemployment rate. As a result, government policies during the COVID-19 pandemic have drastically altered patterns of energy demand around the world. Population confinement has also led to drastic changes in energy use. Daily global $\mathrm{CO}_{2}$ emissions fell by $-17 \%$ as of early April 2020 compared to the mean of 2019 levels (Le Quéré et al., 2020).

In a world that has largely been turned upside down by the coronavirus pandemic, Taiwan has provided an inspiring example of leadership and civic responsibility. Taiwan's epidemic response receives lots of praises from the international community.

Nevertheless, the coronavirus pandemic has taken a heavy toll on the economy. The travel-related and entertainment sectors have been particularly hard hit. Although Taiwan maintains a functioning life (no lockdown restrictions mandated the temporary closure of non-essential shops and businesses), aviation, restaurant, hotel, and tourism sectors all incur dramatic losses. The government promulgated a special relief and revitalization measures on financial support such as stimulating consumption and pushing for investment, providing compensation, subsidies and tax breaks for businesses, individuals and organizations affected by the disease. In this study we'll explore one set of the research questions raised by Helm (2020), that is the relationship between GDP and $\mathrm{CO}_{2}$ emissions under short-term impacts and government adaptive policies.

The policy responses to the COVID-19 coronavirus, esp. lockdowns on different scales and durations, provide an unprecedented economic and environmental experiment. Helm (2020) provides a preliminary assessment and demonstrates that "The most striking correlation in the pandemic is between significant falls in emissions and falls in aggregate demand and aggregate consumption" (p. 23). He then concludes that "The most important lesson from the virus so far is that pollution and GDP are still correlated, not decoupled" (p. 36). Although Helm (2020) has demonstrated that emissions and GDP are highly correlated not just globally but even in Europe, this study intends to provide a local evidence using the case of Taiwan. Moreover, whether there exists an asymmetry of the correlation (or coupling) between GDP and $\mathrm{CO}_{2}$ emission under different periods of prosperity and depression is one of our major research questions for exploration.

Besides the introductory section, the next section compiles the dataset of Taiwan's GDP growth and $\mathrm{CO}_{2}$ emission from 2005 to 2020 . Section three demonstrates the major finding that significant asymmetric correlation (or coupling) exists for prosperous periods and depression periods. The fourth section uses the theory of asymmetric adjustment costs with investment/disinvestment option to provide an explanation for our major finding. Concluding remarks and future research suggestions are provided in the final section.

\section{Taiwan's GDP Growth and $\mathrm{CO}_{2}$ Emission from 2005 to 2020}

Taiwan has initiated and implemented a determined commitment voluntarily for the Paris Agreement. Moreover, the Greenhouse Gas Reduction and Man- 
agement Act (GHGRMA) was promulgated in July 2015, which legislates a 50\% emissions reduction target for 2050 compared to the 2005 levels. The act also implements reduction by setting regulatory goals in stages on a five-year basis as shown in Figure 1.

To explore the relationship between GDP and emissions under periods of prosperity and depression, we compiled Taiwan's GDP growth and emission time series data from 2005 up to 2020 as shown in Table 1 where $\mathrm{CO}_{2}$ emission from 2018 to 2020 and GDP growth rate in 2020 are baseline forecasting results from GEMTEE (The General Equilibrium Model for Taiwanese Economy and Environment).

GEMTEE was jointly developed by the Center for Sustainable Science of the Academia Sinica and the Australian Bureau of Agriculture, Resources and Economics (ABARES) (Chang et al., 2018). It is based on the Monash dynamic computable general equilibrium model, and expanded through investment and population dynamics mechanisms (Dixon and Parmenter, 1996; Dixon and Rimmer, 2002). Based on the Input-Output (IO) database and macroeconomic projections from the expert forecasting organizations, long-term baseline forecasting can be performed (Dixon and Rimmer, 2009; Lin et al., 2015).

From GEMTEE baseline forecasting solved using GEMPACK (Harrison and Pearson, 1996), Taiwan's GDP growth rate is projected at $1.67 \%$ in 2020 and $\mathrm{CO}_{2}$ emission from 2018 to 2020 in Taiwan is 289,293 , and 301 million metric

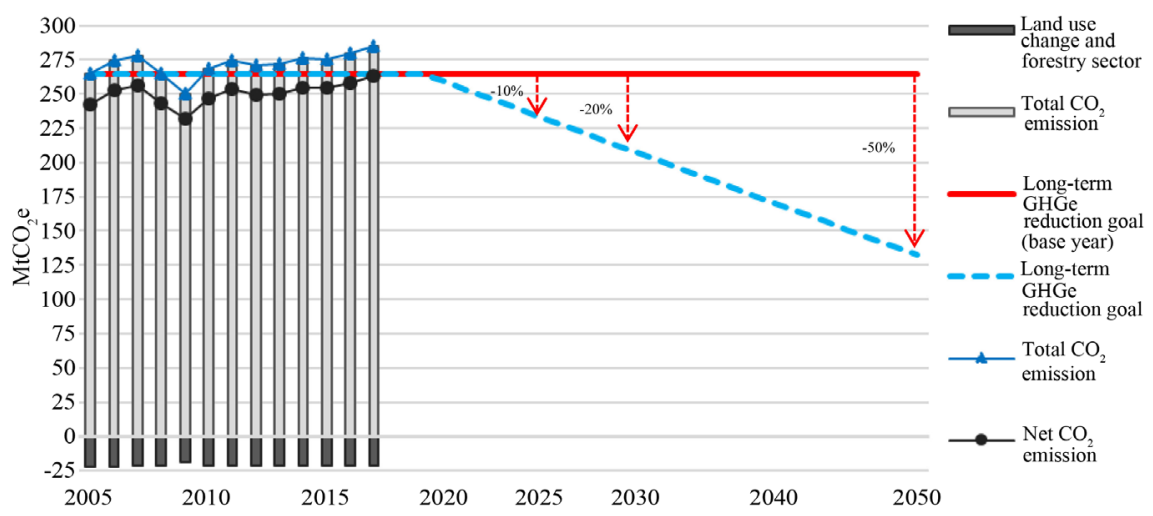

Figure 1. Taiwan GHG emission reduction goal.

Table 1. Taiwan GDP and $\mathrm{CO}_{2}$ emission from 2005 to 2020 .

\begin{tabular}{|c|c|c|c|c|c|c|c|c|c|c|c|c|c|c|c|c|}
\hline Year & 2005 & 2006 & 2007 & 2008 & 2009 & 2010 & 2011 & 2012 & 2013 & 2014 & 2015 & 2016 & 2017 & 2018 & 2019 & $2020(f)$ \\
\hline $\mathrm{CO}_{2}\left(\mathrm{MtCO}_{2} \mathrm{e}\right)$ & 264.7 & 274.3 & 277.7 & 264.7 & 250.6 & 268.4 & 274.9 & 271.0 & 272.0 & 276.3 & 275.8 & 279.5 & 284.8 & 289.1 (f) & $293.4(f)$ & 301.2 \\
\hline $\mathrm{CO}_{2}$ (уоу\%) & 2.63 & 3.63 & 1.25 & -4.67 & -5.33 & 7.10 & 2.42 & -1.41 & 0.35 & 1.59 & -0.17 & 1.34 & 1.89 & $1.82(\mathrm{f})$ & 3.14 (f) & 2.15 \\
\hline $\mathrm{CO}_{2}(\Delta$ уоу $\%)$ & -1.19 & 1.01 & -2.38 & -5.92 & -0.66 & 12.43 & -4.68 & -3.83 & 1.76 & 1.24 & -1.76 & 1.52 & 0.54 & $-0.07(f)$ & 1.32 (f) & -0.99 \\
\hline GDP (billion NTD) & 12,037 & 12,573 & 13,364 & 13,115 & 12,919 & 14,060 & 14,262 & 14,678 & 15,271 & 16,258 & 17,055 & 17,555 & 17,983 & 18,343 & 18,887 & 19,202 \\
\hline GDP (уоу\%) & 3.80 & 4.45 & 6.29 & -1.86 & -1.49 & 8.83 & 1.44 & 2.91 & 4.04 & 6.47 & 4.90 & 2.93 & 2.44 & 2.00 & 2.97 & 1.67 \\
\hline GDP ( $\Delta$ уоу $\%)$ & -2.36 & 0.65 & 1.84 & -8.16 & 0.37 & 10.32 & -7.40 & 1.48 & 1.13 & 2.43 & -1.56 & -1.97 & -0.49 & -0.44 & 0.97 & -1.30 \\
\hline
\end{tabular}

Note: (f) is GEMTEE estimate. The yoy\% refers to the growth rate from previous year, and $\Delta$ yoy\% refers to the difference of yoy\% from previous year. Source: Directorate-General of Budget, Accounting and Statistics (Taiwan) (accessed 31 May 2020) and this study. 
tons, respectively as shown in Table 1 . The carbon dioxide emission statistics is calculated following the Sectoral Approach of the Intergovernmental Panel on Climate Change (IPCC).

Statistical data from most countries have shown that GDP contracted in the first quarter of 2020. The latest world economic outlook reported in April 2020 projected that the world economy would contract sharply by $-3 \%$ in 2020 , a number which is much worse compared to the 2008-2009 financial crisis. For Taiwan, according to IMF (2020) report, the real GDP is projected to fall by $4 \%$ in 2020. However, Taiwan's gross domestic product growth rate in the first quarter of 2020 was $1.59 \%$, which was the best among the Four Asian Tigers (Hong Kong ${ }^{1}$, Singapore ${ }^{2}$, Republic of Korea ${ }^{3}$ and Taiwan). Furthermore, the unemployment rate in the first quarter increased to only $0.04 \%$, which was the lowest given the impacts that COVID-19 brought to the world.

Taiwan's rapid industrial development has led to continuous economic growth. During the 16 years from 2005 to 2020, excluding the three years 2008-2009 (global financial crisis), the economic growth rate ranged from $1.44 \%$ to $8.83 \%$. The global financial crisis refers to the massive financial crisis the world faced from 2008 to 2009. The financial crisis took its toll on individuals and institutions also in Taiwan, with millions of Taiwanese being deeply impacted, and the government was forced to offer bailouts to keep many institutions afloat. Figure 2 demonstrates the trend in GDP growth and $\mathrm{CO}_{2}$ emission growth 2005-2020. However, the continuously high economic growth with limited land and high population density also put a great pressure on the environment. There exists close correlation between GDP (yoy\%) and $\mathrm{CO}_{2}$ emissions (yoy\%), where the yoy\% refers to the growth rate from previous year.

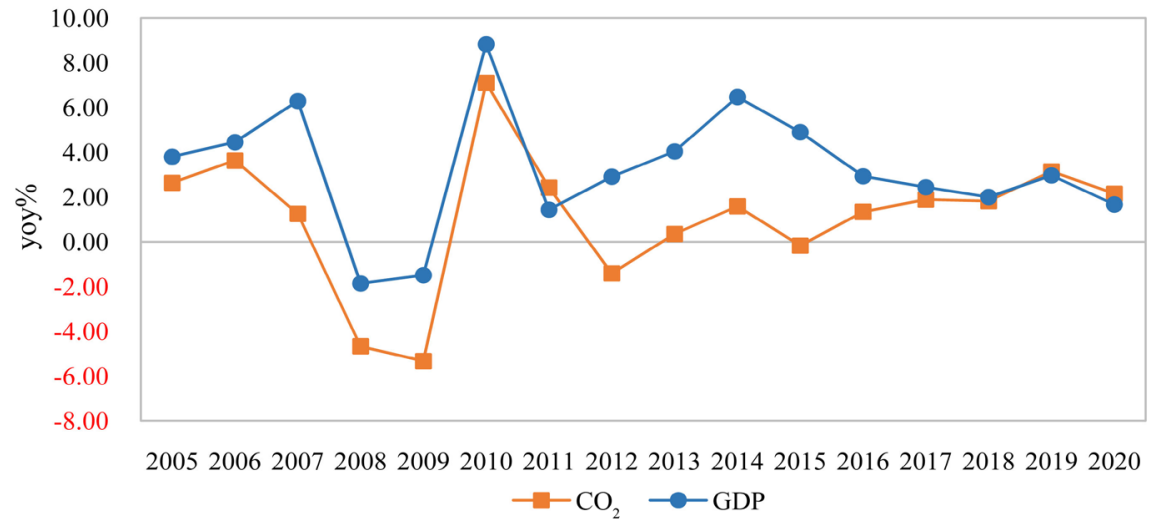

Figure 2. Taiwan's GDP and $\mathrm{CO}_{2}$ growth rate 2005-2020.

\footnotetext{
${ }^{1}$ Hong Kong's GDP contracted by $6.3 \%$ in the first quarter of 2020. (The Government of the Hong Kong Administrative Region of Census and Statistics Department. Available from https://www.censtatd.gov.hk/hkstat/sub/sp250.jsp?tableID=030\&ID=0\&productType=8）（Accessed on 26 May 2020).

${ }^{2}$ Singapore's GDP contracted by $2.2 \%$ in the first quarter of 2020. (Department of Statistics Singapore. Available from https://www.singstat.gov.sg/-/media/files/news/advgdp1q2020.pdf) (Accessed on 26 May 2020).

${ }^{3}$ Republic of Korea's quarterly GDP declined $1.4 \%$ in the three months to March 2020. (The Bank of Korea. Available from https://ecos.bok.or.kr/EIndex_en.jsp) (Accessed on 26 May 2020).
} 
The global food crisis during 2011-2012 witnesses an acceleration of the recession where GDP (yoy\%) drop dramatically. In particular, after $2012 \mathrm{CO}_{2}$ (yoy\%) emission shows no sign of decreasing, but instead increasing and positive (i.e., 0.35 in 2013 and 1.59 in 2014), even when Taiwan's economy was hit hard by the coronavirus pandemic in 2020. Although both growth rates of GDP and carbon dioxide emissions in 2020 are lower than those in 2019, they are still positive simultaneously (i.e., $\mathrm{CO}_{2}($ yoy\%) $>0$ and GDP (yoy\%) $>0$ ). As shown in Table 1 and Figure 2 they show no sign of decoupling.

As shown in Table 1 and Figure 3 where yoy\% refers to the percentage change growth rate from previous year (year on year), and $\Delta$ yoy\% refers to the difference of yoy\% from previous year. For example, yoy\% in 2020 (1.67\%) is calculated from GDP of 2019 divided by GDP of 2020 and then minus one. $\Delta$ yoy\% in $2020(-1.30 \%)$ is the difference between yoy\% in $2020(1.67 \%)$ and yoy\% in 2019 (2.97\%). We found that during the prosperous periods as the GDP $(\Delta y o y \%)>0$ and rises up, there is a positive relationship with $\mathrm{CO}_{2}(\Delta$ yoy\%); but during the recession period where the GDP $(\Delta y$ yoy $\%)<0$ and decreases, the $\mathrm{CO}_{2}$ $(\Delta y o y \%)$ also decreases but with a less amount. It seems that at the local level as shown in Taiwan we may have an asymmetric relationship (or coupling) between GDP $\left(\Delta\right.$ yoy\%) and $\mathrm{CO}_{2}(\Delta$ yoy\%).

\section{Asymmetric Coupling of Taiwan's GDP Growth and $\mathrm{CO}_{2}$ Emissions}

Economic growth has traditionally moved in tandem with pollution. But decoupling of global emissions and economic growth was confirmed by IEA (2016). Some European economies-like Germany, the United Kingdom and France are starting to show signs of decoupling-increasing growth while reducing pollution (OECD, 2020; Cohen et al., 2018; Pilatowska and Wlodarczyk, 2018). It is argued that a major reason for decoupling is their active policies aiming at decarbonizing their economies as well as the structural transformation of their economies towards a greater role for services. However, contrary to the

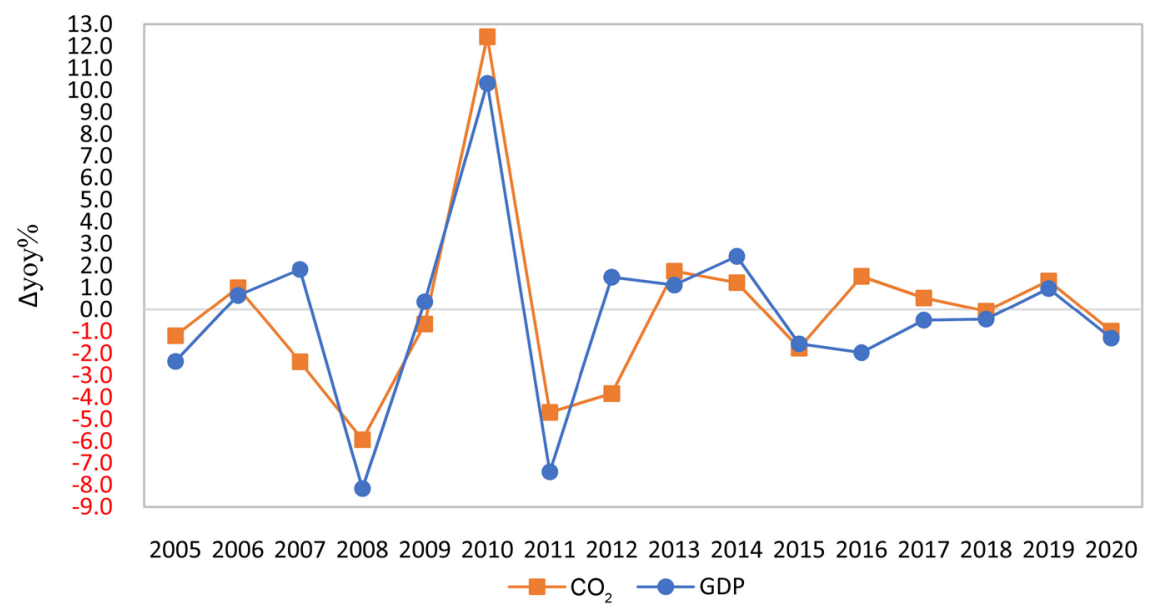

Figure 3. Taiwan's GDP ( $\Delta$ yoy\%) and $\mathrm{CO}_{2}(\Delta$ yoy\%) trends $2005-2020$. 
decoupling claim the evidence in the coronavirus pandemic clearly shows that there exists the striking correlation between significant falls in emissions, falls in aggregate demand, aggregate consumption, and GDP.

Recently Helm (2020) provides an excellent review and preliminary assessment of the environmental impacts of the Coronavirus. He concludes that "The evidence from the pandemic is that it is not the case that decoupling has occurred at the global level, or even at the European level. Emissions and GDP have both fallen sharply" (p. 3).

In order to bring into focus the relationship between the GDP and the $\mathrm{CO}_{2}$ emission in Taiwan, Figure 4 shows in different regions of prosperity and depression, the relationship between the GDP $(\Delta y$ yoy $\%)$ and $\mathrm{CO}_{2}(\Delta$ yoy\% $)$ emission where $\Delta$ yoy\% denotes the difference of yoy $\%$ from last year. The first quadrant above the $\mathrm{x}$-axis (GDP $\Delta$ yoy\%) and to the right of the $\mathrm{y}$-axis $\left(\mathrm{CO}_{2} \Delta \mathrm{yoy} \%\right)$ represents period of prosperity where both GDP $\left(\Delta\right.$ yoy\%) and $\mathrm{CO}_{2}(\Delta$ yoy\%) are positive. Similarly, the third quadrant below the x-axis (GDP $\Delta$ yoy\%) and to the left of the y-axis $\left(\mathrm{CO}_{2} \Delta\right.$ yoy\%) represents period of depression or recession where both GDP $(\Delta$ yoy\% $)$ and $\mathrm{CO}_{2}(\Delta$ yoy\% $)$ are negative.

For simplicity, simple regression is run for data in the first quadrant (the prosperous region) and the third quadrant (the recession region). In the first quadrant, as shown in the upward-sloping line, when economic growth tends to be booming or prosperous, for each percentage point increase in GDP, the $\mathrm{CO}_{2}$ percentage point increases by 1.1963 . On the other hand, in the third quadrant, as shown in the downward-sloping line, when the economy is in recession or depression, the GDP decreases by a percentage point and the $\mathrm{CO}_{2}$ also declines by 0.6789 percentage points. In other words, GDP and $\mathrm{CO}_{2}$ emissions both decrease, but the emissions decrease more slowly. Put simply, both the first quadrant and the third quadrant do not support the claim that GDP and emission have been decoupled in Taiwan. Moreover, there exists a clear asymmetric coupling between GDP and emission. $\mathrm{CO}_{2}$ Emission grows faster in prosperous periods than that in depression periods.

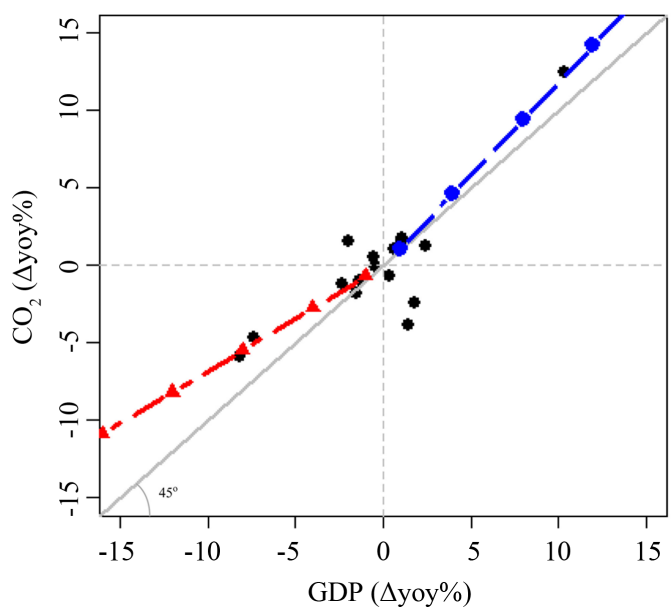

Figure 4. Relationship between GDP and $\mathrm{CO}_{2}$ emission 2005-2020. 
Particularly in the coronavirus pandemic, this asymmetric case provides a more realistic explanation of coupling link between GDP and $\mathrm{CO}_{2}$ emission than the symmetric one as the pandemic continued to worsen around the world. With the coronavirus dominating almost all political and administrative bandwidth, Taiwan promulgated a special act on COVID-19 prevention, relief and revitalization on March 18, 2020 to authorize a special budget, bringing the total bailout package to NTD1.05 trillion. Covering everyone from families and disadvantaged groups to companies and industries, this disease relief package provides a lot of support such as individual tax breaks, household expense subsidies, industrial relief and business tax cuts, with little effort to pursue environmental priorities. Policy support in increasing demand and consumption may be a critical variable in determining the degree of asymmetry.

\section{Policy Responses and Behavioral Adaptation in Taiwan}

The asymmetry in costs of adjustment in the theory of investment and disinvestment may be offered to explain the asymmetric coupling of Taiwan's GDP growth and $\mathrm{CO}_{2}$ Emissions. Hsu and Chang (1990) argue that most of the investment analysis fails to address the depression-prosperity comparison. The analysis of disinvestment is not a trivial duplication of the analysis of investment. Drivers in GDP growth (e.g., policy responses and behavioral adaptation) in the depression periods may be quite different from those in the prosperous period.

In agricultural economics, the theory of asset fixity with an "acquisition/salvage price differentials" mechanism has been frequently used to explain the stylized fact of nonreversible supply response in agricultural production (Johnson, 1956; Edwards, 1959). Hsu and Chang (1990) use the theory of investment and disinvestment with asymmetric adjustment costs to generalize the asset fixity theory as a special case.

The concept of costs of adjustment, transaction costs or sunk costs is so primitive such that its economic interpretation is quite flexible. For example, regulation enforcement, transportation, risk, legal fees, brokerage, spoilage, standard, contracting, insurance, advertisement, and other like costs are also involved. Their magnitudes depend on whether it is an investment or a disinvestment decision, whether the economy is in a prosperous period or a depression period.

If the true relation between GDP and $\mathrm{CO}_{2}$ emission is an asymmetric one, but the policy makers are too optimistic and mistakenly assume the symmetric relation, they may over-estimate the $\mathrm{CO}_{2}$ emission reduction results from their policy responses during the depression period like those in the coronavirus pandemic. That is the current situation encountered in Taiwan.

Taiwan's Greenhouse Gas Reduction and Management Act (GHGRMA), promulgated in 2015 has now been in effect for five years. The Act clearly sets out a GHG reduction target of a $2 \%$ reduction from 2005 levels by 2020 . Due to the COVID-19 linked economic recession and too optimistic about the relation 
between GDP and $\mathrm{CO}_{2}$ emission, the Taiwan government has found that it may fail to reach the GHG reduction goal of $-2 \%$ by 2020 . Taiwan EPA (Environmental Protection Agency) now plans to revise the GHGRMA to improve the regulation enforcement and promote various incentives in order to encourage large enterprises to reduce emissions voluntarily, and to enhance adaptation mechanisms for crisis such as disease, extreme weather and climate change. It is also hoped that the reduction targets will be met through more flexible tools such as emissions trading and offsetting.

Moreover, other policy responses may fail to cut $\mathrm{CO}_{2}$ emissions as expected. For example, in order to keep social distancing in Coronavirus, most of people substitute public transport with the private space of own cars or scooters. When combined with falling oil and gas prices, the huge growth in vehicle numbers and demand for private transport increases the transport sector's demand for energy. Another example is that the Ministry of Transportation and Communications (MOTC) provides fuel price subsidies for taxi, loan projects for aviation industry, and manufacturing stimulation packages.

Finally, consumers are rational and they may have behavioral responses to the Coronavirus pandemic. For example, consumers change their shopping behaviors, which in many cases have led to more online transactions. Consumers also turned to home delivery services for restaurant and grocery food items, and as a result, energy use in delivery services in Taiwan has risen significantly.

\section{Conclusion}

Helm (2020) provides an excellent review and preliminary assessment of the environmental impacts of the Coronavirus. He concludes that "The evidence from the pandemic is that it is not the case that decoupling has occurred at the global level, or even at the European level. Emissions and GDP have both fallen sharply." (p. 3) Using the case of Taiwan, this study provides a local evidence to support Helm (2020)'s proposition. GDP and emissions in Taiwan have been highly correlated in the Coronavirus pandemic. However, we found that there exists a significant asymmetry of the correlation (or coupling) of GDP and $\mathrm{CO}_{2}$ emission under different periods of prosperity and depression from 2005 to 2020.

In a prosperous economic situation, the environmental priority may be justified. However, in a recession or depression situation, the environmental priority has frequently been compromised or set aside. The Coronavirus pandemic provides a unique experiment to bring into focus the asymmetry embedded in the relation between GDP growth and $\mathrm{CO}_{2}$ emission. This study provides a preliminary correlation analysis between GDP growth and $\mathrm{CO}_{2}$ emissions. The correlation between GDP growth and $\mathrm{CO}_{2}$ emissions in the recession or depression period should not be treated as a trivial duplicate of the correlation in the prosperous period. The asymmetry in coupling relation may show that there exist different drivers behind the observed data for prosperous period and depression period. Future research on the causality elements linking up economic factors for the depression-prosperity comparison seems necessary. 
Moreover, $\mathrm{CO}_{2}\left(\mathrm{MtCO}_{2} \mathrm{e}\right)$ and GDP (billion NTD) in 2020 are baseline forecasts from GEMTEE with some ex ante assumptions. The ex post analysis of the asymmetric relationship may be interesting when the official values are announced after 2020. More rigorous statistical testing of asymmetric coupling is of immense value for future study.

\section{Conflicts of Interest}

The authors declare no conflicts of interest regarding the publication of this paper.

\section{References}

Chang, C. C., Hsu, H. S., Lin, H. C., Lee, D. H., Chen, C. C., \& Wu, C. H. (2018). Enhanced GEMTEE (General Equilibrium Model for Taiwan Economy and Environment) for IAM Framework-An Integrated Computable General Equilibrium Model and Database for Appraising Policies toward Sustainable Development. A Progress Report for Sustainability Science Research Program, Academia Sinica, Taiwan.

Cohen, G., Jalles, J. T., Loungani, P., \& Marto, R. (2018). The Long-Run Decoupling of Emissions and Output: Evidence from the Largest Emitters. International Monetary Fund Working Paper.

https://www.imf.org/en/Publications/WP/Issues/2018/03/13/The-Long-Run-Decouplin g-of-Emissions-and-Output-Evidence-from-the-Largest-Emitters-45688

Dixon, P. B., \& Parmenter, B. R. (1996). Chapter 1: Computable General Equilibrium Modelling for Policy Analysis and Forecasting. In H. M. Amman, D. A. Kendrick, \& J. Rust (Eds.), Handbook of Computable Economics (Vol. 1, pp. 3-85). Amsterdam: North Holland. https://doi.org/10.1016/S1574-0021(96)01003-9

Dixon, P. B., \& Rimmer, M. T. (2002). Dynamic General Equilibrium Modelling for Forecasting and Policy: A Practical Guide and Documentation of MONASH, Contributions to Economic Analysis. Amsterdam: North Holland. https://doi.org/10.1108/S0573-8555(2001)256

Dixon, P. B., \& Rimmer, M. T. (2009). Forecasting with a CGE Model: Does It Work? Centre of Policy Studies/IMPACT Centre Working Papers g-197, Victoria University, Centre of Policy Studies/IMPACT Centre.

Edwards, C. (1959). Resource Fixity and Farm Organization. American Journal of Agricultural Economics, 41, 747-759. https://doi.org/10.2307/1234843

Harrison, W. J., \& Pearson, K. R. (1996). Computing Solutions for Large General Equilibrium Models Using GEMPACK. Computational Economics, 9, 83-127.

https://doi.org/10.1007/BF00123638

Helm, D. (2020). The Environmental Impacts of the Coronavirus. Environmental and Resource Economics, 76, 21-38. https://doi.org/10.1007/s10640-020-00426-z

Hsu, S. H., \& Chang, C. C. (1990). An Adjustment-Cost Rationalization of Asset Fixity Theory. American Journal of Agricultural Economics, 72, 298-308.

https://doi.org/10.2307/1242333

International Energy Agency (IEA) (2016). Decoupling of Global Emissions and Economic Growth Confirmed.

https://www.iea.org/news/decoupling-of-global-emissions-and-economic-growth-confi $\underline{\text { rmed }}$

International Monetary Fund (2020). World Economic Outlook, April 2020. 
https://www.imf.org/en/Publications/WEO/Issues/2020/04/14/weo-april-2020

Johnson, G. L. (1956). Supply Functions-Some Facts and Notions. In E. Heady et al. (Eds.), Agricultural Adjustment Problems in a Growing Economy (pp. 74-93). Ames, IA: Iowa State University Press.

Le Quéré, C., Jackson, R. B., Jones, M., Smith, A., Abernethy, S., Andrew, R. M., De-Gol, A. J., Willis, D. R., Shan, Y., Canadell, J. G., Friedlingstein, P., Creutzig, F., \& Peters, G. P. (2020). Temporary Reduction in Daily Global $\mathrm{CO}_{2}$ Emissions during the COVID-19 Forced Confinement. Nature Climate Change, 10, 647-653.

https://doi.org/10.1038/s41558-020-0797-x

Lin, H. C., Lee, H. L., Hsu, S. M., Lin, K. J., Lee, D. H., Chang, C. C., \& Hsu, S. H. (2015). Baseline Forecasting for Taiwan's Population in the Face of Low Fertility Rate and Ageing Problems. Taiwan Economic Forecast and Policy, 46, 113-156.

Organization for Economic Co-Operation and Development (OECD) (2020). Environmental Indicators. https://www.oecd.org/site/envind

Pilatowska, M., \& Wlodarczyk, A. (2018). Decoupling Economic Growth from Carbon Dioxide Emissions in the EU Countries. Montenegrin Journal of Economics, 14, 7-26. https://doi.org/10.14254/1800-5845/2018.14-1.1 